\title{
Acute renal failure associated with diflunisal
}

\author{
J. G. WHARTON \\ B.Sc., M.R.C.P.
}

\author{
D. O. OLIVER \\ F.R.C.P., F.R.A.C.P.
}

\author{
M. S. DUNNILL \\ F.R.C.P., F.R.C.Path.
}

Renal Unit, Churchill Hospital, and Department of Pathology, John Radcliffe Hospital, Oxford

\begin{abstract}
Summary
The case of a 44-year-old man with acute oliguric renal failure due to tubulo-interstitial nephritis after 3 months' diflunisal is reported. The possible mechanisms are discussed.

\section{Introduction}

Diflunisal has been reported as causing acute allergic interstitial nephritis (Chan et al., 1980) resulting in acute oliguric renal failure. $A$ case of acute renal failure due to tubulo-interstitial nephritis after 3 months of diflunisal is reported here. Recently, phenylakalonic acids with analgesic and antiinflammatory properties such as fenoprofen and naproxen have been reported as causing tubulointerstitial nephritis manifested by acute renal failure and often accompanied by nephrotic syndrome but without signs of hypersensitivity such as fever, rash, and eosinophilia (Wendland, Wagoner and Holley, 1980). Diflunisal is not a phenylakalonic acid but is the difluorophenyl derivative of salicylic acid; it has analgesic and anti-inflammatory properties but with fewer side effects than salicylic acid.
\end{abstract}

\section{Case report}

A 44-year-old man was admitted with acute oliguric renal failure. He had been treated for the previous 3 months with diflunisal $(250 \mathrm{mg}$ twice/day) for low backache due to lumbar spine osteoarthrosis. The only other analgesic treatment was occasional paracetamol and dextropropoxyphene (Distalgesic). Over 3 months he had lost $35 \mathrm{~kg}$ which was associated with anorexia and nausea. One week before admission he was noted to be oliguric, hypertensive $(200 / 115 \mathrm{mmHg})$ and was subsequently admitted with symptoms and signs of fluid overload due to oliguria. Investigations at this time showed: haemoglobin $11.7 \mathrm{~g} / \mathrm{dl}$; white cell count $11.0 \times 10^{9} / 1$; eosinophils $224 \times 10^{6} / 1$; ESR $30 \mathrm{~mm} / \mathrm{hr}$; urea 30.5 วิ $\mathrm{mmol} / \mathrm{l}$; creatinine $1651 \mu \mathrm{mol} / \mathrm{l}$; potassium $6.43^{\circ}$ $\mathrm{mmol} / \mathrm{l}$; serum amylase 88 Somogyi units; urine contained no casts; no red cells but 10 neutrophils, no eosinophils and no growth. Antistreptolysin $\mathrm{O}_{-}^{-}$ titre 50 i.u./ml; IgG 16.5 g/l; IgA 3.8 g/l; IgM 1.1 g/l Th antinuclear factor negative; $C_{3} 122 \mathrm{mg} / \mathrm{dl}, C_{4} 54 \stackrel{\mathbb{O}}{O}$ $\mathrm{mg} / \mathrm{dl}$; hepatitis $B$ surface antigen negative; chest radiograph, cardiomegaly plus congestion; intra $₹$ venous urogram with tomograms, no obstruction, $\overrightarrow{0}$ poor nephrogram. A renal biopsy showed tubuteinterstitial nephritis with no eosinophil infiltrate. Diflunisal had been stopped 2 days before admissiơno to this renal unit. Within $24 \mathrm{hr}$ of starting peritoneals dialysis a diuretic phase had resulted in a 4-litreo urine output in $24 \mathrm{hr}$. Dialysis was therefore dis-0 continued and intravenous saline was needed to@ keep pace with urine losses. Recovery was uneventful| $\overrightarrow{0}$ and the patient was discharged with a serum creatin- 3 ine $290 \mu \mathrm{mol} / 1$; clearance $44 \mathrm{ml} / \mathrm{min}$. Three months? following acute renal failure a further renal biopsy? was performed which showed tubular necrosis ando interstitial fibrosis with a striking lack of inter stitial cellular infiltration similar to the previous biopsy. At this time the patient was hypertensive with a creatinine of $350 \mu \mathrm{mol} / \mathrm{l}$ and clearance of $35 \mathrm{ml} / \mathrm{min}$.

\section{Comment}

Clinically and histologically there has been an incomplete recovery from tubulo-interstitial nephritis due to diflunisal. There was nothing to suggest a hypersensitivity reaction (Chan et al., 1980) and 0 therefore corticosteroids were not used. Diflunisat has similar anti-inflammatory analgesic properties to acetylsalicylic acid and there is a cross-over ino allergic sensitivity reactions between aspirin ancक diflunisal (Tempero, Cirillo and Steelman, 1977) $\stackrel{\mathcal{D}}{+}$ Aspirin, indomethacin, fenoprofen (Wendland et al. 1980) and diflunisal (Steelman et al., 1976) al 
decrease renal synthesis and excretion of prostaglandin $E_{1}$. It has therefore been postulated that renal vasoconstriction from inhibition of $P G_{1}$ synthesis might reduce renal blood flow and result in tubular necrosis (Johnson, 1980). This may explain the rapid recovery from acute oliguric renal failure but does not account for interstitial fibrosis seen in this case.

\section{References}

Chan, L.K., Winearls, C.G., Oliver, D.O. \& Dunnill, M.S. (1980) Acute interstitial nephritis and erythroderma associated with diflunisal. British Medical Journal, 280, 84.
JoHnson, W.J. (1980) Nephrotoxicity of non-steroidal antiinflammatory drugs. Proceedings. Mayo Clinic, 55, 120.

Steelman, S.L., Smit-sibinga, C.T.H., Schulz, P., Vanden Heuvel, W.J.A. \& Tempero, K.F. (1976) The effect of diflunisal on urinary prostaglandin excretion, bleeding time and platelet aggregation in normal human subjects. (Abst.) XIIIh International Congress of Internal Medicine, Forssa, Finland.

Tempero, K.F., Cirillo, V.J. \& Steelman, S.L. (1977) Diflunisal: a review of pharmacokinetic and pharmacodynamic properties, drug interaction and special tolerability studies in humans. British Journal of Clinical Pharmacology, 4, 31.

Wendland, M.L., Wagoner, R.D. \& Holley, L.F. (1980) Renal failure associated with fenopron. Proceedings. Mayo Clinic, 55, 103. 